Ann. Biol. anim. Bioch. Biophys., I97I, 11 (4), 657-668.

\title{
ÉTUDE DU DÉVELOPPEMENT CHEZ LA TRUITE. ÉVOLUTION DE LA TENEUR EN ACIDES NUCLÉIQUES DANS DIVERSES FRACTIONS CORPORELLES
}

\author{
P. LUQUET \\ avec la collaboration technique de Geneviève Han NEQUART \\ Station de Recherches de Nutrition, \\ Centre national de Recherches zootechniques, I. N. R. A., \\ 78 - Jouy-en-Josas \\ RÉSUMÉ
}

La croissance de la musculature complète, du foie, des viscères et des parties ossifiées de la truite arc-en-ciel, dont le poids augmente de $20 \mathrm{~g}$ à $200 \mathrm{~g}$ a été étudiée en suivant:

- l'évolution de la concentration et de la teneur totale en acides nucléiques,

- l'évolution de la taille des cellules et de la quantité de protéines qu'elles contiennent.

Lorsque le poids vif de la truite est multiplié par Io, le poids du muscle l'est par I2 et le nombre des cellules musculaires par 7,7. Dans le même intervalle, la taille des cellules n'a été multipliée que par I,56. La croissance du muscle est donc due essentiellement à l'hyperplasie bien que dans l'intervalle de poids $58-96 \mathrm{~g}$, l'hypertrophie puisse expliquer momentanément $70 \mathrm{p}$. Ioo du gain de poids.

La croissance du foie est aussi due principalement à l'hyperplasie qui explique toujours 85 p. Ioo du gain de poids. Lorsque le poids du foie est multiplié par 7 la taille des hépatocytes n'augmente que de $28 \mathrm{p}$. 1 oo.

Dans ce tissu et cet organe, comme dans les autres fractions étudiées, la quantité totale d'ADN augmente proportionnellement au poids frais. Aucun ralentissement de la multiplication cellulaire n'est constaté lorsque les truites atteignent le poids de $200 \mathrm{~g}$.

\section{INTRODUCTION}

Les principes de constance de la quantité moyenne d'acide désoxyribonucléique dans une cellule diploïde établis par BoIVIN et VENDRELY (I948), ont permis à de nombreux auteurs, à la suite d'ENEsco (I959), de mesurer l'évolution du nombre de cellules dans un tissu ou un organe par l'évolution de la quantité totale d'ADN qu'il renferme. Cette mesure a également permis de connaître la part de l'accroisse- 
ment pondéral d'un tissu ou d'un organe qui revient respectivement à la multiplication et au grandissement cellulaires (DURAND et al., I965). La plupart des travaux ont été appliqués à des tissus et organes de divers mammifères. Pour les poissons, les connaissances dans ce domaine sont très restreintes. En effet, si la concentration en acides nucléiques de différents tissus et organes des poissons a été étudiée (B⿺辶Hm, TARR, I957 ; IMURA, SAITO, I968) ainsi que l'évolution de leur teneur au cours du cycle sexuel (CREelman, Tomlinson, I959; Berdyshev et al., I969; ImURA et SAITO, I969) ou au cours du jeûne (Bouche et al., I970), peu d'auteurs ont suivi l'évolution de la teneur en acides nucléiques au cours de la croissance postembryonnaire. LOVE (I958), après avoir noté que la concentration en ADN dans les myotomes du muscle de morue est moins élevée que dans le tissu conjonctif qui les sépare (myocommes), constate que, lorsque le poisson augmente de longueur, la concentration en ADN ne varie pas en proportion inverse de celle de la taille des fibres musculaires dont le nombre demeure constant; il en conclut que, au cours de la croissance de la morue, il s'effectue une certaine synthèse d'ADN. L'existence et la permanence de cette dernière ont été récemment démontrées (LUQUET, DURAND, r970) dans le muscle de la truite arc-en-ciel dont le poids varie de $20 \mathrm{~g}$ à $3400 \mathrm{~g}$. Il a ainsi été montré que l'hyperplasie explique la majeure partie de l'accroissement pondéral du muscle de la truite. Toutefois, ces travaux n'ont porté que sur une partie de la musculature des poissons, il est donc intéressant de connaître ce quj se passe au niveau de la musculature complète et d'autres tissus ou organes.

C'est dans le but d'élargir ainsi nos connaissances que nous avons étudié les variations quantitatives en acides nucléiques chez la truite arc-en-ciel Salmo gairdnerii RICHARDSON au cours de sa croissance dans les fractions suivantes: la musculature complète, le foie, l'ensemble viscères + sang et enfin le reste comprenant la tête, le squelette axial, les arêtes, les nageoires et la peau que nous appellerons pour simplifier, parties ossifiées.

\section{I. - MATÉRIEL E'T MÉTHODES}

\section{I. - Méthodes d'études}

La consommation des truites, leur croissance pondérale, et leur composition corporelle ont été suivies. Pour chacune des fractions précitées, les évolutions du poids frais, de la teneur en acides nucléiques et en protéines ont été déterminées. Ces données nous permettent de mesurer pour chacune des formations :

- l'évolution du nombre de cellules par celle de la quantité d'ADN (ADN total),

- l'évolution de la taille des cellules par celle du rapport poids frais/ADN total,

- l'évolution de la quantité d'ARN par cellule par le rapport ARN/ADN,

- l'évolution des quantités de protéines par cellule par celle du rapport protéines/ADN.

\section{2. - Matériel animal}

Les truites utilisées sont issues d'œufs d'une seule femelle fécondés par la laitance d'un seul mâle. Elles ont reçu un régime à $50 \mathrm{p}$. Ioo de protéines jusqu'au poids de ıo $\mathrm{g}$. A ce stade, roo d'entre elles sont placées dans un bac en matière plastique d'une contenance utile de $\mathrm{r}_{5} \mathrm{O}$ 1, alimenté en eau de la ville à un débit de $5 \mathrm{1}$ /minute. Elles reçoivent ad libitum un régime semisynthétique (LUQUET, 197I) renfermant $40 \mathrm{p}$. Ioo de protéines. Les poissons sont sacrifiés au poids de $20 \mathrm{~g}, 5^{8} \mathrm{~g}, 96 \mathrm{~g}$ et $205 \mathrm{~g}$ (tabl. I) par rupture des vertèbres cervicales. Ils sont ensuite 
séchés, pesés, puis saignés par incision de l'aorte ventrale; seules sont retenues les truites dont le poids s'écarte le moins du poids moyen du lot expérimental.

Le prélèvement des différents tissus ou organes se fait de façon quantitative. Les échantillons provenant des différents poissons sont congelés immédiatement dans l'azote liquide; l'ensemble des opérations dure de 20 à 30 minutes par animal. Les fractions prélevées sont regroupées et conservées au froid jusqu'au broyage qui précède immédiatement les analyses.

\section{3. - Méthodes analytiques}

a) Acides nucléiques.

Les acides nucléiques séparés par la méthode de Schmidt et Thannhauser sont estimés par spectrophotométrie dans $1^{\prime} \mathrm{UV}$ après séparation de leurs composés sur colonnes échangeuses d'ions suivant la méthode décrite par Durand et al. (1969).

Les quantités d'ADN et d'ARN sont exprimées par la somme (en micromoles) de leurs bases constitutives.

b) Composition corporelle.

- l'eau est déterminée par séchage à l'étuve à $95^{\circ} \mathrm{C}$ jusqu'à poids constant,

- l'azote total est déterminé par la méthode de Kjeldahl sur les échantillons frais,

- l'azote protéique est déterminé par la méthode précédente sur le résidu sec obtenu après extraction des éléments acido-solubles par l'acide trichloracétique io p. Ioo,

- les lipides sont estimés par la différence : matière sèche - (protéines brutes + cendres).

\section{II. - RÉSULTATS}

Pour faciliter l'exposé des résultats, nous appelons :

- première période, la période allant de 30 à 37 semaines durant laquelle les truites croissent de 20,2 à $58,4 \mathrm{~g}$,

- deuxième période, la période allant de 37 à 45 semaines durant laquelle les truites croissent de 58,4 à $96, \mathrm{I} \mathrm{g}$,

- troisième période, la période allant de 45 à 60 semaines durant laquelle les truites croissent de $96, \mathrm{I}$ à $205,5 \mathrm{~g}$.

\section{I. - Croissance globale des Truites (tabl. I)}

\section{a) Croissance et consommation.}

Les truites ont multiplié leur poids par Io en 30 semaines (20 g à $205 \mathrm{~g}$ ). La courbe de croissance dont la concavité est tournée vers le haut indique que, durant toute la période expérimentale, les truites ont présenté une croissance auto-accélérée (BRODY, 1945). Le gain de poids journalier moyen est de $0,63 \mathrm{~g}$ pour la première période, de $0,72 \mathrm{~g}$ pour la deuxième période et de $0,99 \mathrm{~g}$ pour la troisième période. La consommation journalière augmente en absolu avec le gain de poids ; si au contraire elle est exprimée en pourcentage du poids vif, ce qui mesure l'appétit, elle est de 2,2 p. Ioo au cours de la première période, de $I, 5 \mathrm{p}$. Ioo au cours de la deuxième période et de I,I p. IOO au cours de la dernière période. L'indice de consommation moyen est de $I, 65$.

b) Composition corporelle.

La proportion d'eau diminue légèrement au cours de la première période (73 p. Ioo à 70,5 p. IOO) ; elle ne varie pas par la suite. Au contraire, la teneur en protéine, stable au cours des deux premières périodes ( 14,8 p. Ioo à I 4,4 p. roo), augmente de 6 p. Ioo 
par la suite. La part qui revient aux cendres, tout en demeurant faible, s'accroît légèrement jusqu'à ce que les truites atteignent le poids de $96 \mathrm{~g}(2,2 \mathrm{p}$. I0o à $2,7 \mathrm{p}$. I00), elle revient ensuite à la valeur initiale. La proportion de lipides croit légèrement jusqu'à ce que les truites atteignent le poids de $96 \mathrm{~g}$ (Io p. IOo à I3,2 p. I0O) pour diminuer légèrement ensuite.

\section{TABLEAU I}

Caractéristique des Truites au moment du sacrifice

\begin{tabular}{|c|c|c|c|c|}
\hline Lot $n^{0}$ & 1 & 2 & 3 & 4 \\
\hline Age (semaines) & 30 & 37 & 45 & 60 \\
\hline Poids vif . . . . . . . & 20,2 & 58,4 & 96,1 & 205,5 \\
\hline Nombre de truites $\ldots \ldots \ldots \ldots \ldots \ldots \ldots$ & 10 & 10 & 9 & 8 \\
\hline Eau $\%$ du poids frais $\ldots \ldots \ldots \ldots \ldots \ldots$ & 73 & 70,6 & 69,7 & 69,7 \\
\hline $\mathrm{N} \times 6,25 \%$ du poids frais $\ldots \ldots \ldots \ldots$ & 14,8 & 14,8 & 14,4 & 15,4 \\
\hline Cendres $\%$ du poids frais $\ldots \ldots \ldots \ldots \ldots$ & 2,2 & 2,4 & 2,7 & 2,3 \\
\hline Lipides $\%$ du poids frais $\ldots \ldots \ldots \ldots \ldots$ & 10,0 & 12,2 & 13,2 & 12,6 \\
\hline Eau + lipides $\%$ du poids frais $\ldots$. & 83 & 82,8 & 82,9 & 82,3 \\
\hline
\end{tabular}

Eñ résumé, la composition globale des truites demeure pratiquement constante au cours de la période étudiée. Deux faits sont cependant à souligner, d'une part, le faible engraissement des truites de $205 \mathrm{~g}$, et, d'autre part, la remarquable constance de la proportion eau + lipides.

\section{2. - Croissance des différents tissus et organes}

a) Foie (tabl. 2).

- Le poids du foie, qui représente de 2,7 à I,8 p. Ioo de la masse corporelle, croît moins vite que celui de la truite entière. L'allométrie négative se manifeste principalement jusqu'à ce que les truites pèsent $96 \mathrm{~g}$. Au cours de la dernière période, la vitesse de croissance de cet organe et de l'animal entier est identique. Au total, le poids du foie n'a été multiplié que par 7,4 alors que le poids de la truite l'a été par Io.

- La concentration en ADN (ADN $\mu \mathrm{M} / \mathrm{g}$ sec et dégraissé) varie peu au cours de la première période $(52,9 \mu \mathrm{M}$ à $54,7 \mu \mathrm{M})$. Elle diminue de $25 \mathrm{p}$. Ioo au cours de la deuxième période pour demeurer stable ensuite $(43,7 \mu \mathrm{M}$ à $40, \mathrm{I} \mu \mathrm{M})$. La quantité totale d'ADN contenue dans cet organe est multipliée par 6,2 au cours de la période étudiée. La courbe représentative de cette évolution en fonction du poids de la truite (fig. I) est pratiquement linéaire. Le foie représente de 4,5 à $6 \mathrm{p}$. Ioo de l'ADN total du poisson (tabl. 3).

- La concentration en ARN dans le foie est beaucoup plus élevée que pour les autres tissus et organes. Elle est stable au cours de la première période $(142,9 \mu \mathrm{M}$ à $136,7 \mu \mathrm{M})$; au cours de la deuxième période elle augmente de $20 \mathrm{p}$. Ioo et ne varie plus par la suite. La quantité totale d'ARN dans cet organe augmente plus vite que la quantité d'ADN ; elle est en effet multipliée par 9,5 soit pratiquement par le même coefficient que le poids vif du poisson. 
TABLEAU 2

Évolution de certaines caractéristiques dans différents tissus et organes de la Truite arc-en-ciel en croissance

\begin{tabular}{|c|c|c|c|c|c|}
\hline & No des lots & Foie & Muscles & $\begin{array}{c}\text { Tête } \\
+ \\
\text { nageoires } \\
+ \\
\text { squelette axial } \\
+ \\
\text { peau }\end{array}$ & $\begin{array}{c}\text { Viscères } \\
+ \\
\text { sang }\end{array}$ \\
\hline $\begin{array}{l}\text { Poids frais } \% \text { du } \\
\text { poids vif }\end{array}$ & $\begin{array}{l}1 \\
2 \\
3 \\
4\end{array}$ & $\begin{array}{l}2,7 \\
2,3 \\
1,8 \\
1,8\end{array}$ & $\begin{array}{l}52,9 \\
56,3 \\
55,7 \\
59,1\end{array}$ & $\begin{array}{l}36,4 \\
33,8 \\
32,3 \\
30,8\end{array}$ & $\begin{array}{r}9,1 \\
10,1 \\
10,3 \\
11,3\end{array}$ \\
\hline $\begin{array}{l}\text { Poids } \operatorname{SD}(\hat{i}) \% d u \\
\text { poids frais }\end{array}$ & $\begin{array}{l}1 \\
2 \\
3 \\
4\end{array}$ & $\begin{array}{l}13,8 \\
11,8 \\
14,4 \\
15,4\end{array}$ & $\begin{array}{l}17,4 \\
16,7 \\
15,8 \\
16,5\end{array}$ & $\begin{array}{l}13,6 \\
13,9 \\
12,8 \\
13,0\end{array}$ & $\begin{array}{l}7,5 \\
6,9 \\
9,2 \\
8,9\end{array}$ \\
\hline $\begin{array}{l}\text { ADN/g SD } \\
\text { ( } \mu \text { M-bases) }\end{array}$ & $\begin{array}{l}1 \\
2 \\
3 \\
4\end{array}$ & $\begin{array}{l}52,9 \\
54,7 \\
43,7 \\
40,1\end{array}$ & $\begin{array}{l}7,6 \\
7,6 \\
5,6 \\
5,1\end{array}$ & $\begin{array}{l}38,0 \\
24,5 \\
24,9 \\
21,6\end{array}$ & $\begin{array}{l}78,9 \\
83,7 \\
80,4 \\
79,9\end{array}$ \\
\hline $\begin{array}{l}\text { ADN total } \\
\text { ( } \mu \mathrm{M} \text {-bases })\end{array}$ & $\begin{array}{l}1 \\
2 \\
3 \\
4\end{array}$ & $\begin{array}{c}3,44 \\
7,65 \\
10,2 \\
21,5\end{array}$ & $\begin{array}{l}12,3 \\
37,7 \\
45,3 \\
94,4\end{array}$ & $\begin{array}{r}33,3 \\
60,9 \\
94,8 \\
164,5\end{array}$ & $\begin{array}{r}9,6 \\
30,9 \\
69,7 \\
151,8\end{array}$ \\
\hline $\begin{array}{c}\text { ARN/g SD } \\
(\mu \mathrm{M} \text {-nucléotides })\end{array}$ & $\begin{array}{l}1 \\
2 \\
3 \\
4\end{array}$ & $\begin{array}{l}142,9 \\
136,7 \\
167,5 \\
164,7\end{array}$ & $\begin{array}{l}16,9 \\
19,5 \\
18,6 \\
25,0\end{array}$ & $\begin{array}{l}33,7 \\
29,1 \\
32,7 \\
37,5\end{array}$ & $\begin{array}{r}90,0 \\
97,4 \\
99,2 \\
111,3\end{array}$ \\
\hline $\begin{array}{c}\text { ARN total } \\
\text { ( } \mu \mathrm{M} \text {-nucléotides) }\end{array}$ & $\begin{array}{l}1 \\
2 \\
3 \\
4\end{array}$ & $\begin{array}{r}9,3 \\
19,1 \\
39,2 \\
88,4\end{array}$ & $\begin{array}{r}27,5 \\
96,6 \\
150,1 \\
462,7\end{array}$ & $\begin{array}{r}29,5 \\
72,4 \\
124,2 \\
286,1\end{array}$ & $\begin{array}{r}10,9 \\
36,0 \\
86,0 \\
211,5\end{array}$ \\
\hline$\frac{\mathrm{ARN}}{\mathrm{ADN}}$ & $\begin{array}{l}1 \\
2 \\
3 \\
4\end{array}$ & $\begin{array}{l}2,70 \\
2,50 \\
3,83 \\
4,10\end{array}$ & $\begin{array}{l}2,24 \\
2,56 \\
3,32 \\
4,90\end{array}$ & $\begin{array}{l}0,89 \\
1,19 \\
1,31 \\
1,74\end{array}$ & $\begin{array}{l}1,14 \\
1,16 \\
1,23 \\
1,39\end{array}$ \\
\hline$\frac{\text { Poids frais }(\mathrm{mg})}{\overline{\mathrm{ADN}} \text { total }(\mu \mathrm{M} \text {-bases })}$ & $\begin{array}{l}1 \\
2 \\
3 \\
4\end{array}$ & $\begin{array}{l}136,6 \\
155,5 \\
159,3 \\
161,6\end{array}$ & $\begin{array}{rl} & 761,2 \\
& 787,7 \\
1 & 132 \\
1 & 189\end{array}$ & $\begin{array}{l}193,1 \\
293,1 \\
313,5 \\
355,8\end{array}$ & $\begin{array}{l}168,6 \\
172,2 \\
135,4 \\
141,3\end{array}$ \\
\hline 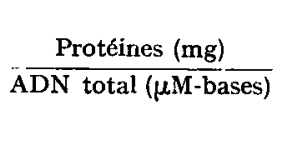 & $\begin{array}{l}1 \\
2 \\
3 \\
4\end{array}$ & $\begin{array}{l}16,3 \\
15,6 \\
20,0 \\
21,6\end{array}$ & $\begin{array}{l}113,6 \\
118,3 \\
156,6 \\
171,9\end{array}$ & $\begin{array}{l}23,5 \\
36,1 \\
36,4 \\
42,9\end{array}$ & $\begin{array}{l}11,1 \\
10,4 \\
11,1 \\
10,9\end{array}$ \\
\hline
\end{tabular}

(i) Sec dégraissé. 
- Le rapport ARN/ADN présente un léger minimum $(2,5)$ lorsque les truites pèsent $58 \mathrm{~g}$; il augmente fortement par la suite pour atteindre 4, Io chez les poissons de $200 \mathrm{~g}$.

- La valeur du rapport poids frais/ADN augmente peu ( 28 p. Ioo) au cours de toute la période de croissance considérée; les $2 / 3$ de cette augmentation sont d'ailleurs acquis dès que les truites atteignent le poids de $58 \mathrm{~g}$ (fig. 2). Au contraire, le rapport des protéines du foie à l'ADN demeure stable au cours de la première période. Il augmente de $25 \mathrm{p}$. Ioo au cours de la deuxième période et ne varie plus ensuite.

\section{TABLEAU 3}

Répartition de l'ADN entre les différents compartiments corporels chez la Truite, selon le poids corporel

\begin{tabular}{|c|c|c|c|c|}
\hline Poids des truites & 20,2 & 58,4 & 96,1 & 205,5 \\
\hline Foie $\ldots \ldots \ldots \ldots \ldots \ldots \ldots \ldots$ & 6 & 5,5 & 4,5 & 5 \\
\hline Muscle $\ldots \ldots \ldots \ldots \ldots \ldots \ldots \ldots$ & 21 & 27,5 & 20,5 & 22 \\
\hline $\begin{array}{c}\text { Peau }+ \text { Tête }+ \text { nageoires }+ \text { Squelette } \\
\text { axial } \ldots \ldots \ldots \ldots \ldots \ldots\end{array}$ & 56,5 & 44,5 & 43 & 38 \\
\hline Viscères + Saug $\ldots \ldots \ldots \ldots \ldots \ldots$ & 16,5 & 22,5 & 32 & 35 \\
\hline Truite entière $\ldots \ldots \ldots \ldots \ldots \ldots \ldots$ & 100 & 100 & 100 & 100 \\
\hline
\end{tabular}

b) Muscle (tabl. 2).

- Le poids frais du muscle augmente plus vite que le poids vif du poisson. En effet, lorsque celui-ci est multiplié par ro, le poids de la musculature l'est par I2. Parallèlement, la part qui revient à ce tissu dans la masse corporelle totale augmente de 53 p. 100 à 59 p. Ioo.

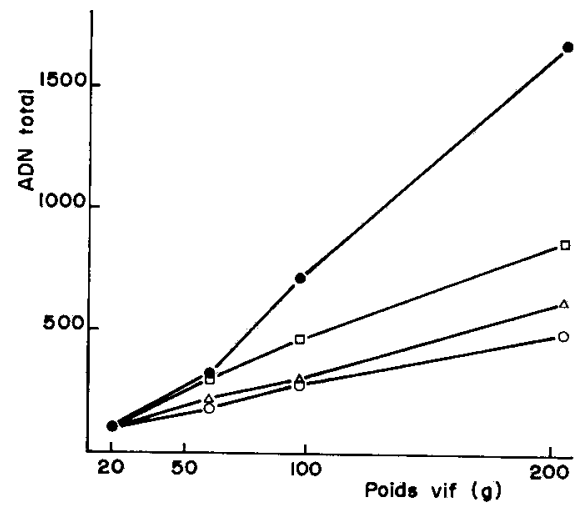

FIG. I. - Evolution en fonction du poids vif, quantité totale d'ADN' dans les differents compartiments corporels de la Truite
․ Muscle
$\triangle$ Foie
- Viscères + sang
- Parties ossifiées. 
- $\mathrm{L}_{\mathbf{a}}$ concentration en $\mathrm{ADN}$ demeure toujours faible et égale à $7,6 \mu \mathrm{M}$ jusqu'à ce que les truites atteignent le poids de $58 \mathrm{~g}$. Elle diminue encore de $25 \mathrm{p}$. roo par la suite pour atteindre 5,I $\mu \mathrm{M}$ chez les truites les plus âgées. La quantité totale d'ADN contenue dans ce tissu (fig. I) est multipliée par 7,7 pendant toute la période considérée. La moitié de cette augmentation est acquise dès que les truites pèsent $58 \mathrm{~g}$; la synthèse d'ADN est donc intense au cours de la première période. Elle se ralentit au contraire au cours de la deuxième période pour reprendre activement durant la dernière période. Bien que la musculature représente plus de $50 \mathrm{p}$. Ioo du poids du corps, elle ne contient que 25 p. Ioo de l'ADN total de la truite (tabl. 3). Ceci découle de la faible concentration en ADN du muscle.

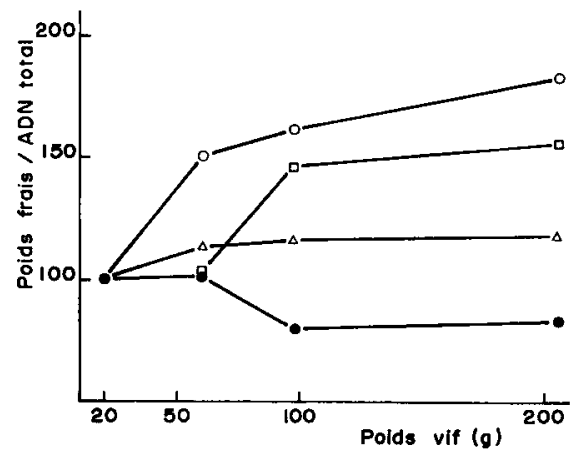

FIG. 2. - Evolution en fonction du poids vif, du rapport poids frais/ADN total. dans les diflerents compartiments corporels de la Truite

$\square$ Muscle
$\Delta$ Foie
- Viscères + sang
- Parties ossifiées.

- La concentration en ARN augmente de I6,9 $\mu \mathrm{M}$ à 25,0 $\mu \mathrm{M}$ lorsque le poids de la truite passe de 20 à $205 \mathrm{~g}$. Soixante-quinze p. Ioo de cette augmentation sont acquis au cours de la dernière période considérée. La quantité totale d'ARN dans le muscle augmente considérablement avec le poids de la truite. En effet, lorsque celui-ci est multiplié par Io, l'ARN total est multiplié par I6,8.

- La valeur du rapport ARN/ADN augmente progressivement de 2,24 à 3,32 jusqu'à ce que les truites atteignent le poids de $96 \mathrm{~g}$. Au-delà, l'augmentation de ce rapport est considérable puisque la valeur obtenue pour les truites de $205 \mathrm{~g}$ est de 4,90 .

- Le rapport poids frais/ADN évolue peu ( 3 p. Ioo) jusqu'à ce que les truites atteignent le poids de $5^{8} \mathrm{~g}$. A partir de ce stade, la valeur de ce rapport augmente rapidement pour être multipliée par $\mathrm{I}, 56$ à $96 \mathrm{~g}$; elle varie peu par la suite (fig. 2 ). Le rapport protéines/ADN suit une évolution parallèle avec une faible augmentation de sa valeur jusqu'au poids de $58 \mathrm{~g}$. Cependant, l'augmentation totale de la valeur de ce rapport n'a été que de 50 p. Ioo.

c) Viscères + sang (tabl. 2).

- Les viscères et le sang représentent de 9,I à II,3 p. Ioo du poids de la truite. Cette fraction présente une croissance plus rapide que l'organisme entier car sa masse a été multipliée par 13.5 au cours de toute la période étudiée. 
- La concentration en $\mathrm{ADN}$ est supérieure à $79 \mu \mathrm{M} / \mathrm{g} \mathrm{SD}$ et pratiquement constante au cours de la croissance ; l'amplitude des variations ne dépasse pas 6 p. roo.

- La quantité totale d'ADN augmente plus vite que le poids frais de ces fractions (fig. I), elle a été en effet multipliée par 16 . Par ailleurs, la participation de l'ADN total des viscères et du sang à l'ADN total du poisson double au cours de la période considérée et passe ainsi de $\mathbf{6} 6,5$ p. Ioo à 35 p. Ioo (tab1. 3)

- La teneur en ARN augmente avec le poids des poissons. Cette augmentation est de $20 \mathrm{p}$. Ioo sur l'ensemble de la période considérée. La quantité totale d'ARN, sous l'action conjuguée de l'augmentation de la concentration et de l'augmentation en pourcentage du poids frais par rapport au poids vif, augmente considérablement et est multipliée par 19,5 .

- Le rapport $A R N / A D N$ est faible mais augmente de façon continue passant ainsi de $I, I_{4}$ à $I, 39$.

- Le rapport poids frais/ADN demeure assez stable jusqu'à ce que les truites atteignent le poids de $5^{8} \mathrm{~g}$ mais diminue de $20 \mathrm{p}$. Ioo par la suite. Le rapport protéines/ADN demeure au contraire très stable, les valeurs extrêmes étant de I0,4 et II,I.

\section{d) Fractions ossifiées (tabl. 2).}

- La vitesse d'accroissement pondéral des fractions ossifiées est plus faible que celle de la truite entière ; leur poids a été multiplié par 9,I et le pourcentage par rapport au poids vif diminue de 36,4 à 30,8 p. Ioo.

- La concentration en $A D N$ de ces tissus est assez élevée pour les truites de $20 \mathrm{~g}\left(3^{8} \mu \mathrm{M} / \mathrm{g} \mathrm{SD}\right)$ mais diminue pratiquement de moitié par la suite. La quantité totale d'ADN varie pratiquement linéairement en fonction du poids de la truite (fig. I), son augmentation est cependant faible car son coefficient d'accroissement n'est que de 4,6. La participation de 1'ADN total de ces fractions à 1'ADN total de la truite diminue d'ailleurs au cours de la croissance et passe de $5^{8,5}$ p. Ioo à $3^{8} \mathrm{p}$. IOo lorsque les truites croissent de $20 \mathrm{~g}$ à $205 \mathrm{~g}$.

- La concentration en ARN qui a pour valeur initiale $33,3 \mu \mathrm{M} / \mathrm{g} \mathrm{SD}$ diminue de $I_{5} \mathrm{p}$. Ioo jusqu'à ce que les truites pèsent $58 \mathrm{~g}$ puis augmente de $30 \mathrm{p}$. Ioo chez les truites plus âgées. La quantité totale d'ARN augmente deux fois plus vite que la quantité d'ADN. Elle est en effet multipliée par 9,7 dans la même période.

- Le rapport ARN/ADN est faible mais augmente de façon continue avec le poids du poisson passant ainsi de 0,89 pour les truites de $20 \mathrm{~g}$ à $\mathrm{I}, 74$ lorsque les poissons ont atteint le poids de $205 \mathrm{~g}$.

- L'évolution du rapport poids frais/ADN montre un accroissement de $50 \mathrm{p}$. Ioo lorsque les truites pèsent $5^{8} \mathrm{~g}$, ce rapport a atteint à ce stade les $66 \mathrm{p}$. Ioo de sa valeur maximale ; sur l'ensemble de la période de croissance considérée il a été multiplié par I,84 (fig. 2).

- Le rapport protéines/ADN augmente de $54 \mathrm{p}$. Ioo durant la première période de croissance considérée $(23,5$ à $36, \mathrm{I})$, il semble demeuter stable jusqu'au poids de $96 \mathrm{~g}(36,4)$ pour augmenter légèrement ensuite. 


\section{III. - DISCUSSION}

\section{I. - Acides nucléiques et multiplication cellulaire}

Nous avons appliqué à l'étude de la croissance du muscle latéro-dorsal de la truite une méthode, maintenant classique, basée sur le principe que le nombre de noyaux d'un tissu est proportionnel à la quantité d'ADN qu'il contient (LUQUET, DURAND, I970). La taille des cellules est appréciée par le rapport du poids frais du tissu au nombre de noyaux. Cette méthode nous a permis de montrer que, dans le muscle latéro-dorsal de truite l'hyperplasie (multiplication cellulaire) se manifeste avec une intensité égale tout au long de la croissance du poisson et que l'hypertrophie (grandissement cellulaire) ne peut expliquer qu'une très faible partie de l'accroissement pondéral de ce muscle.

Cette méthode d'étude peut être étendue sans inconvénient à l'étude de la croissance de la musculature totale, les difficultés dans ce cas-là étant d'avoir un prélèvement $\mathrm{du}$ muscle quantitatif. Nous verrons également plus loin qu'aucun cas de polyplö̈die n'a été mis en évidence dans les cellules hépatiques des poissons, cet organe se prête donc également à l'application d'une telle méthode. Par contre, en ce qui concerne les deux autres fractions que nous avons retenues, les viscères et le sang d'une part, et ce que nous avons appelé les parties ossifiées d'autre part, 1'hétérogénéité des tissus et des organes est telle qu'une telle méthode ne peut apporter que peu de renseignements. En conséquence, nous limiterons notre discussion aux modalités de la croissance du muscle et du foie en soulignant uniquement que dans le reste du corps la synthèse d'ADN se manifeste de façon continue pendant toute la période étudiée.

\section{2. - Croissance du muscle}

\section{a) Croissance pondérale.}

Le muscle constitue en poids le tissu le plus important chez la truite arc-en-ciel, il représente en effet plus de $53 \mathrm{p}$. Ioo de la masse corporelle. Cette proportion est nettement supérieure à celle présentée par la musculature des mammifères car celle-ci ne participe que pour $45 \mathrm{p}$. Ioo du poids de l'animal (MunRo, I969). La croissance du muscle complet de la truite présente une allométrie positive par rapport à celle du poisson : en effet, le pourcentage du poids frais du muscle au poids vif de l'animal augmente de $53 \mathrm{p}$. Ioo à $59 \mathrm{p}$. Ioo lorsque le poids de la truite passe de $20 \mathrm{~g}$ à $200 \mathrm{~g}$. Au contraire, LUSK (I969) observe que chez la truite commune vivant en rivière, la proportion du muscle diminue lorsque le poids du poisson augmente jusqu'à $200 \mathrm{~g}$. Cet auteur n'a cependant pas rapporté l'âge des truites et n'a pu évaluer leur vitesse de croissance. Ces paramètres sont importants car MANN (I959) a montré que la proportion de muscle augmente avec la vitesse de croissance de la carpe et de la truite.

b) Hyperplasie-hypertrophie.

Les rôles respectifs de l'hyperplasie et de l'hypertrophie peuvent être appréciés par un calcul simple (DuRAND et al., I965) dont les résultats figurent dans le tableau 4. 
Au cours de la première période, correspondant au passage de $20 \mathrm{~g}$ à $5^{8} \mathrm{~g}, 1^{\prime}$ hyperplasie assure l'essentiel de la croissance ( $97 \mathrm{p}$. roo) tandis que la taille des cellules n'a augmenté que de $3 \mathrm{p}$. Ioo, ce qui est négligeable.

\section{TABLEAU 4}

Intervention relative en $p .100$ de la multiplication et du grandissement cellulaires dans la croissance du foie et du muscle de la Truite arc-en-ciel

\begin{tabular}{ll|c|c|c}
\hline \hline Intervalle & $\begin{array}{c}20-58 \mathrm{~g} \\
(\%)\end{array}$ & $\begin{array}{c}58-96 \mathrm{~g} \\
(\%)\end{array}$ & $\begin{array}{c}96-205 \mathrm{~g} \\
(\%)\end{array}$ \\
\hline \multirow{2}{*}{ Foie $\quad$} & Myperplasie ... & 85 & 92 & 98 \\
Mypertrophie .. & 15 & 8 & 2 \\
& & 97 & 31 & 93 \\
\hline
\end{tabular}

$\mathrm{Au}$ cours de $1 \mathrm{a}$ deuxième période $\left(5^{8} \mathrm{~g}\right.$ à $\left.96 \mathrm{~g}\right)$ la synthèse d'ADN se ralentit et l'hypertrophie assure $69 \mathrm{p}$. Ioo du gain de poids. Pendant ce temps, la taille des cellules a augmenté de $44 \mathrm{p}$. Ioo alors que la quantité de protéines associée à chaque noyau n'a augmenté que de $32 \mathrm{p}$. Ioo. Au cours de cette période de grandissement cellulaire, le muscle fixe préférentiellement des lipides ainsi que le montrent les variations de composition corporelle et de composition du gain de poids.

Au cours de la troisième période on observe une reprise très forte de l'hyperplasie qui assure $93 \mathrm{p}$. Ioo de la croissance. Les cellules augmentent peu de taille (5 p. roo) et fixent préférentiellement des protéines. Ceci se traduit par une forte proportion de protéines dans le gain de poids du poisson soit I6,3 p. Ioo au lieu de I3,8 p. Ioo au cours de la période précédente.

Ce phénomène de freinage momentané de l'hyperplasie et de prépondérance de l'hypertrophie entre le poids de $50 \mathrm{~g}$ et $100 \mathrm{~g}$, ne doit être qu'accidentel ou tout au moins transitoire. En effet, nous n'avons rien observé de tel au cours de la croissance de la musculature épaxiale.

Comparée à celle des mammifères, la musculature de la truite se caractérise par une faible teneur en $\mathrm{ADN}$ dans le tissu sec et dégraissé (5 à $8 \mu \mathrm{M} / \mathrm{g} \mathrm{SD})$ analogue à celle observée dans le muscle des membres postérieurs du rat déjà adulte $(6,7 \mu \mathrm{M} / \mathrm{g} \mathrm{SD})$ alors que chez le Rat de $70 \mathrm{~g}$ cette teneur est trois fois plus élevée (DuRAND, I967 a). Inversement, le rapport ARN/ADN, est plus élevé dans le muscle de truites que dans le muscle des mammifères. Ce rapport $\mathrm{ARN} / \mathrm{ADN}$ varie en effet de 2,24 à 4,90 chez la Truite alors qu'il ne dépasse pas 2,26 chez le Rat et le Porc. Toutefois, dans la musculature épaxiale de la truite d'un poids supérieur à $800 \mathrm{~g}$, le rapport $\mathrm{ARN} / \mathrm{ADN}$ diminue pour se stabiliser autour de I (LUQUET, DURAND, 1970).

\section{3. - Croissance du foie}

Le cas de polyploïdie des noyaux hépatiques chez les Poissons semble très rare à l'inverse de ce qui se passe chez les Mammifères. En effet, FAUTREz et MOERMAN (1954) n'ont trouvé chez Lebistes reticulatus qu'une seule classe de noyaux diploïdes 
De même, Bachmann et CowDEN (I967) n'ont détecté que I6 cas de noyaux qui semblaient tétraploïdes sur $I 500$ observations d'hépatocytes appartenant à 15 espèces de poissons. Le pourcentage de polyploïdes semble donc ne guère dépasser I $\mathrm{p}$. Ioo des cas ; ceci nous permet de mesurer avec une grande sécurité, l'évolution du nombre de cellules hépatiques chez la Truite par l'évolution correspondante de la quantité d'ADN.

Nos résultats indiquent que $1 \mathrm{a}$ croissance du foie est due essentiellement à l'hyperplasie qui explique plus de $85 \mathrm{p}$. Ioo du gain de poids. Au-delà de roo $\mathrm{g}$ on peut considérer le grandissement cellulaire comme négligeable. Les cellules hépatiques n'ont cependant pas encore atteint un équilibre définitif car à ce stade, d'une part, le rapport ARN/ADN augmente toujours, et, d'autre part, elles s'enrichissent encore en protéines. Lorsque les truites pèsent $200 \mathrm{~g}$, la valeur du rapport $\mathrm{ARN} / \mathrm{ADN}$ est de 4,I, valeur inférieure à celle observée $(6,4)$ par IMURA et SAITo (I968) dans le foie de truites arc-en-ciel femelles en période d'activité sexuelle. Ces auteurs (IMURA et SAITO, I969) ont, par ailleurs, observé que le rapport ARN/ADN est de I à 2 fois plus élevé chez les saumons femelles que chez les mâles. Les évolutions des caractéristiques du foie de la Truite au cours de sa croissance ne diffèrent guère de celles du foie du Rat et du Porc. Les concentrations en ADN, en ARN, le rapport ARN/ADN et la taille des cellules sont en effet du même ordre de grandeur. De même, lorsque le poids vif de chacun de ces animaux est multiplié par Io : soit une croissance de $20 \mathrm{~g}$ à $200 \mathrm{~g}$ pour la Truite, de $39 \mathrm{~g}$ à $393 \mathrm{~g}$ pour le Rat, et de $5,7 \mathrm{~kg}$ à $50 \mathrm{~kg}$ pour le Porc, la quantité totale d'ADN est multipliée par 6,5 dans le foie de chacune de ces espèces. Par contre, si dans cet intervalle la taille des hépatocytes de Porc ne varie guère $(6,5 \mathrm{p}$. IOO) (DURAND et $a l$., I967 b), le grandissement cellulaire est plus intense chez le Rat (20 p. Ioo) (DuRAND et al., I965) et chez la Truite (28 p. roo). Ce dernier point constitue la différence la plus marquée dans l'évolution des caractéristiques du foie au cours de la croissance chez les_Mammifères et les Poissons.

Reçu pour publication en mai 1971.

\author{
SUMMARY \\ DEVELOPMENT IN THE TROUT. CHANGES IN NUCLEIC ACID \\ CONTENTS OF DIFFERENT BODY FRACTIONS
}

\begin{abstract}
Growth of total muscle, liver, viscera and ossified parts of rainbow trout growing in weight from $20 \mathrm{~g}$ to $200 \mathrm{~g}$ was studied. Development in fresh weight, in concentration of total nucleic acid content and in size of cells and the amount of protein which they contained was recorded.

The trout were fed to appetite on a diet with 40 per cent protein and they multiplied their weight by ro times in 30 weeks. Purine bases of DNA and the nucleotides of RNA were estimated by ion-exchange column chromatography after separation by the method of Schmidt and Tannhauser.

Total muscle increased more quickly than the whole fish and was from 53 to 59 per cent of liveweight. DNA content was low ( 7 to $5 \mu$ moles basic ADN per $\mathrm{g}$ fat-free dry weight). The RNA/DNA ratio changed from 2.2 to 4.9 as liveweight increased from 20 to $200 \mathrm{~g}$. Total DNA (proportional to the number of cells) increased in proportion to the weight of muscle; while the latter increased 12 -fold, the former increased 7.7 -fold and at the same time the size of the cells increased only r.56-fold. Thus most of the gain in weight was because of an increase in number of cells (hyerplasia).
\end{abstract}


Growth of liver was less rapid than that of liveweight up to $98 \mathrm{~g}$; after that growth was isometric. Concentration of DNA was high (40 to $55 \mu$ moles basic DNA per $g$ fat-free dry weight) the same as seen in mammals. The RNA/DNA ratio was minimum (2.50) at $5^{8} \mathrm{~g}$ liveweight. Growth of liver was essentially due to hyperplasia which always accounted for more than 85 per cent of the gain in weight. The size of the cells increased by 28 per cent.

In the other fractions studied, as in liver and muscle, amount of DNA increased in proportion to fresh weight of the tissue or organ. No slowing down of cell multiplication was seen when the trout had reached $200 \mathrm{~g}$ weight.

\section{RÉFÉRENCES BIBLIOGRAPHIQUES}

Bachmann K., Cowden R. R., 1967. Specific DNA amounts and nuclear size in fish hepatocytes and erythrocytes. Trans. Am. microsc. soc., 86, 463-47I.

Berdyshev G. D., Baranova S. N., Korotaev G. K., I969. Variations de la teneur en acides nucléiques dans les tissus et organes de l'Oncorhynchus gorbuscha (W.) à différents stades de la migration de fraye (en russe). Vop. Ikhtiol., 9, 153-162.

Bluhm H. M., TARr H. L. A., I957. Marine fish muscle nucleic acids. Can. J. Biochem. Physiol., 35, 767-769.

Botvin A., VendRely R., VendRely C., I948. L'acide désoxyribonucléique du noyau cellulaire dépositaire des caractères héréditaires; arguments d’ordre analytique. C. R. Acad. Sci., 226, ro61-1062.

Bovche G., CReAch Y., GAS N., I970. Le jeûne et la réalimentation chez la Carpe (Cyprinus carpio L.). I. Influence sur les acides nucléiques du foie. Arch. Sci. Physiol., 24, 243-25 I.

Brody S., 1945. Bioenergetics and growth. New York, Reinhold Publ. corp.

Creelman V. R., Tomlinson N., I959. Biochemical studies on Sockeye salmon during spawning migration. VI. Ribonucleic and desoxyribonucleic acid. J. Fish Res. Bd. Can., 16, 421-428.

Durand G., Fauconneau G., Penot E., I965. Étude biochimique de la croissance de l'intestin grêle, du foie et de la carcasse du Rat ; rôles respectifs de la multiplication et du grandissement cellulaires. Ann. Biol. anim. Bioch. Biophys., 5, 163-187.

Durand G., Fauconneau G., Penot E., I967 $a$. Croissance des tissus du Rat et réduction de l'apport énergétique de la ration; influence sur la teneur en acides nucléiques. Ann. Biol. anim. Bioch. Biophys., 7, I45-155.

Durand G., Fauconneau G., Penot E., I967 b. Évolution des teneurs en acides nucléiques et en protéines du foie de Porc au cours de la croissance postnatale. Bull. Soc, Chim. Biol., 49, 361-37o.

Durand G., Fauconneau G., Penot E., 1969. Répartition des cellules entre les tissus du rat adulte, préalablement soumis à une sous-nutrition énergétique temporaire à deux stades de la croissance. Ann. Biol. anim. Bioch. Biophys., 9, 55-73.

ENESco M., 1959. Increase in number of nuclei and the mean cell size during postnatal growth of the heart of male Sherman rats. Ant. Rec., 133, 272.

Fautrez J., Moerman J., 1954. La teneur en acide désoxyribonucléique des cellules hépatiques chez Lebistes reticulatus. Comp. Rend, Assoc. Anat., 80, 554-557.

Imura K., Sarto T., I968. Nucleic acid contents in various tissues of some fishes. Bull. Fac. Fish. Hokkaido Univ., 19, I32-139.

IMURA K., SAIto T., I969. Seasonal variations in the metabolic activities of tissue constituents of some fishes. I. Changes in nucleic acid contents of some tissues of Kokanee salmon, Oncorhynchus nerka f. Kenerlyi. Bull. Fac. Fish. Hokkaido Univ., 20, zо2-2 10.

Love R. M., I958. Studies on the north sea cod. II. Desoxyribose nucleic acid in the musculature. J. Sci. Fd. Agric., 8, 199-203.

LuQUeT P., I97I. Efficacité des protéines en relation avec leur taux d'incorporation dans l'alimentation de la truite arc-en-ciel. Ann. Hydrobiol (sous presse).

Luguet P., Durand G., I97o. Évolution de la teneur en acides nucléiques de la musculature épaxiale au cours de la croissance chez la Truite arc-en-ciel (Salmo gairdnerii); rôles respectifs de la multiplication et du grandissement cellulaires. Ann. Biol. anim. Bioch. Biophys., 10, 481-492.

Lusk S., I 969 . The utility value of the Brown trout, Salmo trutta m. fario L., and the Grayling, Thymallus thymallus L., Zool. listy, 18, 81-92.

ManN H., r959. Der Anteil des Essbaren bei Karpfen, Schleien und Forellen. Der Fishwirt, 11, I-6.

Munro H. N., 1969. In Munro H. W., Mammalian protein metabolism vol. III, Part III, chap. 25, Academic Press, New York, London. 